\title{
Parental Investment by Sex on Ifaluk
}

\author{
Laura L. Betzig
}

Museum of Zoology, University of Michigan, Ann Arbor

Paul W. Turke

Department of Anthropology, University of Michigan, Ann Arbor

\begin{abstract}
Trivers and Willard (Science 179:90-92, 1973) predict that where investment by parents in good condition increases the fitness of sons more than that of their sisters, while the opposite is true of parents in poor condition, parents with much to invest will favor sons, while those with little will favor daughters. Patterns of parent-child association on Ifaluk atoll are consistent with this prediction.
\end{abstract}

KEY WORDS: Parental investment; Sex ratio; Status.

\section{INTRODUCTION}

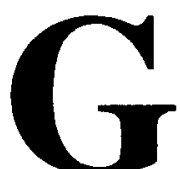

enerally, parents should have evolved to allocate resources according to offspring reproductive potential (see Fisher 1958, p. 159). Trivers and Willard (1973) have suggested specifically that where, for a given amount of investment (Trivers 1972), sons in good condition will outreproduce their sisters, and daughters in poor condition will outreproduce their brothers, sons should be favored by parents with much to invest, and daughters by parents with little. Parents may expend greater investment on the favored sex by biasing the sex ratio of their offspring, and/or by investing more in surviving offspring.

Much evidence and discussion have been addressed to this prediction (Trivers and Willard 1973; reviews in Clutton-Brock and Albon 1982; Trivers 1985). Some tentative evidence suggests that human parents may determine offspring sex before birth according to their ability to invest (see CluttonBrock and Albon 1982; Trivers 1985). Better evidence suggests that humans invest differentially in children after birth. In some highly stratified human groups, male-biased sex ratios have been effected among high-status parents by female infanticide, abuse, and neglect (explicity predicted in Alexander

Received June 7, 1985; accepted September 27, 1985

Address reprint requests to: Laura L. Betzig, Museum of Zoology, University of Michigan, Ann Arbor, MI 48109. 
1974; evidence in Dickemann 1979; Voland 1984, 1986; Boone 1986). And, both within and across cultures, high-status parents have been shown to disinherit daughters compared to their brothers (e.g., Dickemann 1979; Van den Berghe and Mesher 1980; Boone 1986).

To date, observational evidence of a sex bias in investment in children according to parental condition has not been presented for humans; it is presented here. This study has been made of the people of Ifaluk, a Western Caroline Island.

\section{METHODS}

\section{Site}

Ifaluk is an atoll encircling an area 0.939 statute miles square, lying at $7^{\circ} 15^{\prime}$ north latitude and $147^{\circ}$ east longitude, about 350 miles east-southeast of the political center of the archipelago, Yap, and about 400 miles south of the nearest economic center, Guam. People on Ifaluk continue to subsist almost entirely by fishing, breadfruit and coconut harvesting, and taro cultivation. Many aspects of Ifaluk's culture, like its subsistence economy, were at the time of our study much as they had been traditionally (Burrows and Spiro 1953; Bates and Abbott 1958; Lutz 1980; Turke 1985).

The small land area of Ifaluk atoll is passed down by use: women, who work the land, share that right with their sisters, daughters, and granddaughters. Similarly, women, their immediate families, and those of their sisters, daughters, and granddaughters, live together on bugot, the estates on which they work together to prepare food, weave together much of Ifaluk's material culture, and care for young children. Canoe houses and canoes, individual coconut palms, and the vital and prestigious lore of navigators and master builders are, on the other hand, commonly used by, and considered the property of, men. The latter two of these, at least, may be passed on from father to son. Public property, including pathways, island peripheries, large fishing seines, and the meeting house, are all "the property of the chiefs." The single most important aspect of "property" on Ifaluk, and in this part of the Pacific, however, is that chiefs have the authority to determine how, and to what end, all of the resources on the atoll will be used, irrespective of their nominal "ownership" (see Burrows and Spiro 1957, pp. 146-156; Alkire 1974).

Status, then, may be the most important determinant of resource access on Ifaluk. Parents are differentiated by status in two ways. Traditionally, each clan is headed by a male chief, who inherits his rank from his mother's brother; this system is still intact. There are now five clan chiefs on Ifaluk (one old woman shares that position for a lack of suitable male heirs), two local village chiefs, two chiefly "advisors," and ten likely adult successors. (The greater number of successors than chiefs reflect uncertainty over 
whether a brother or sister's son will inherit.) Material benefits accrue to holders of chiefly office, including annual tribute offerings, a favorable balance in house-to-house food sharing (which occurs at least once a week), extra fish at island-wide redistributions (which happen at least once a month), and a more leisurely life (Betzig 1986a).

Since the post-war creation of the U.N. Pacific Trust Territories, a second kind of status has been created on Ifaluk, in the form of governmentpaid teaching, nursing, and construction positions. Thirteen native men are presently so employed on a full-time basis; four others have been paid part time; and eight others were once, but are no longer, paid. As the only other source of cash income on Ifaluk is by the sale of copra, at about $\$ 10$ to $\$ 20$ per extended family household with each arrival of the field trip ship, the relative buying power of salaried individuals is substantial. Six of the thirteen present full-time positions are filled by sons or brothers of chiefs and previously salaried men (Turke and Betzig 1985). Men of either traditional, chiefly status or modern, salaried status have significantly higher reproductive success than do men lacking either kind of status (Turke and Betzig 1985).

In analysis that follows, observed associations among all parents resident on the larger of Ifaluk's two inhabited islets, Falalop, and their children, wherever resident on the atoll, are considered. This includes nine high-status fathers (three with traditional status, five presently or previously salaried, and one both), eight mothers with husbands of high status (two traditional, five salaried, one both), and 17 fathers and 19 mothers with neither traditional nor salaried status.

\section{Scan}

The amount of time parents spend with children has been considered a significant indicator of investment by Fisher (1958, pp. 158-159) and Trivers (1972); it is also a tractable measure. Data on parent-child associations were collected during an instantaneous scan study, made on a daily 1-2-hour circuit of Falalop islet over 48 consecutive days from September to November 1983. On each circuit, identifications of all individuals associating in groups of two or more were recorded. Scans were begun at randomly determined half-hour intervals during daylight hours; as virtually all daytime activities on Ifaluk are done outdoors, and as the circuit covered the islet, every kind of activity done on Ifaluk was within sight of this walk (details in Betzig and Turke 1986).

Because these were instantaneous, rather than extended, or focal, scans (Altmann 1974), we were unable to determine which individuals initiated associations. We would expect that, generally, approaches would more often be made by solicitors to bestowers of favors. Children generally fit into the former category, and parents into the latter. It also seems likely that on Ifaluk, as elsewhere, associations would be both more frequent and more 
Table 1. Parent-Child Association by Parent's Status and Child's Sex

\begin{tabular}{|c|c|c|c|c|}
\hline & \multicolumn{3}{|c|}{ High Status } & \multirow{2}{*}{$\begin{array}{l}\text { Low Status } \\
\text { All Others }\end{array}$} \\
\hline & $\begin{array}{l}\text { Chiefs, } \\
\text { Advisors, and } \\
\text { Successors }\end{array}$ & $\begin{array}{l}\text { Ever-Salaried } \\
\text { Men }\end{array}$ & $\begin{array}{c}\text { Chiefs, } \\
\text { Advisors, } \\
\text { Successors, } \\
\text { and Salaried }\end{array}$ & \\
\hline \multicolumn{5}{|l|}{ Fathers } \\
\hline $\begin{array}{l}\text { Percent of parent-child } \\
\text { associations with sons } \\
(n)\end{array}$ & $\begin{array}{l}67.7^{a} \\
(65)\end{array}$ & $\begin{array}{l}66.1^{b} \\
(59)\end{array}$ & $\begin{array}{l}67.7^{\circ} \\
(99)\end{array}$ & $\begin{array}{l}36.6 \\
(41)\end{array}$ \\
\hline \multicolumn{5}{|l|}{ Mothers } \\
\hline $\begin{array}{l}\text { Percent of parent-child } \\
\text { associations with sons } \\
(n)\end{array}$ & $\begin{array}{l}62.0^{d} \\
(71)\end{array}$ & $\begin{array}{l}49.2^{e} \\
(65)\end{array}$ & $\begin{array}{l}52.9^{\prime} \\
(104)\end{array}$ & $\begin{array}{l}34.3 \\
(102)\end{array}$ \\
\hline
\end{tabular}

protracted where they served the interests of both parties, and that, in the case of a conflict of interest, they would more often take place at the discretion of favor bestowers. This would be so regardless of who more often approached whom (cf. Fairbanks and McGuire 1985).

\section{RESULTS}

On Ifaluk, husbands of high traditional and salaried status and their wives do in fact associate significantly more often with sons than do parents without such status, who tend to associate more often with daughters. Table 1 shows strong biases in these associations consistent with Trivers and Willard's prediction. Data on the productivity of members of each age sex category suggest that the net flow of investment on Ifaluk is down the generations at all ages (Turke 1985). Accordingly, associations between parents and children of all ages have been taken into account in Table 1 . When associations between parents and children under 16 only are considered, results remain in each case in the predicted direction, but are not as strong. (For traditional vs. low-status fathers, $\mathrm{MLR}=7.9206, p=0.0049$; for salaried vs. low status fathers, $M L R=6.4183, p=0.0113$; for traditional vs. low status mothers, MLR $=3.3770, p=0.0661$; for salaried vs. low status mothers, MLR = $0.0987, p=0.7534$.)

Table 2, which includes data for all of Ifaluk atoll, shows that virtually none of these biases are accountable to sex ratio. Figures in Table 2 are replicated in the scan sample group. (For high-status fathers, percent sons $=40.0[n=60]$; for low-status fathers, percent sons $=40.0[n=65]$; for 
Table 2. Sex Ratio by Parent's Status

\begin{tabular}{|c|c|c|c|c|}
\hline & \multicolumn{3}{|c|}{ High Status } & \multirow{2}{*}{$\begin{array}{l}\text { Low Status } \\
\text { All Others }\end{array}$} \\
\hline & $\begin{array}{l}\text { Chiefs, } \\
\text { Advisors and } \\
\text { Successors }\end{array}$ & $\begin{array}{c}\text { Ever-Salaried } \\
\text { Men }\end{array}$ & $\begin{array}{l}\text { Chiefs, } \\
\text { Advisors, } \\
\text { Successors, } \\
\text { and Salaried }\end{array}$ & \\
\hline \multicolumn{5}{|l|}{ Fathers } \\
\hline $\begin{array}{l}\text { Percent Sons } \\
(n) \\
\text { Mothers }\end{array}$ & $\begin{array}{l}48.4 \\
(95)\end{array}$ & $\begin{array}{l}46.7 \\
(105)\end{array}$ & $\begin{array}{r}47.9 \\
(167)\end{array}$ & $\begin{array}{l}48.0 \\
(150)\end{array}$ \\
\hline $\begin{array}{l}\text { Percent Sons } \\
(n)\end{array}$ & $\begin{array}{l}51.3 \\
(78)\end{array}$ & $\begin{array}{l}49.0 \\
(100)\end{array}$ & $\begin{array}{l}51.0 \\
(151)\end{array}$ & $\begin{array}{l}46.8 \\
(222)\end{array}$ \\
\hline
\end{tabular}

high-status mothers, percent sons $=44.0[n=50]$; and for low-status mothers, percent sons $=42.3[n=77].)^{1}$

\section{DISCUSSION}

Several alternatives to Trivers and Willard's prediction might explain these findings. First, since on Ifaluk the frequency of mother-child, though not father-child, association decreases with the age of children $(b=-2.7221$, $p=0.0760$ regressing $\vee y$ on $x$ ), differences in children's ages might explain the result. This is not the case. In fact, though there is no difference in sons' ages (MLR $=0.4898, p=0.9211$ ), high-status mothers tend to have younger daughters $(\mathrm{MLR}=6.6499, p=0.0839)$; this dampens what may be a stronger preference on the part of high-status mothers to associate with sons.

It is also possible that unobserved association patterns differed from those seen. It seems unlikely, though, that when we weren't watching, highstatus parents associated preferentially with daughters and low-status parents with sons. It also seems unlikely that the quality of associations systematically contradicted their frequency. "Quality" is, in this case, difficult to assess. We were, however, able to note that sons and daughters of all ages of high and low status are equally likely to be at work while associating with their parents. (Children are physically working during about $18 \%$ of these associations, and parents are working during about 57\%.) And, in 4 months of observation, we saw altogether only five agonistic interactions (cf. Lutz 1982), only one of which took place during an instantaneous scan, and involved a mother admonishing a small child to stay out of the water.

\footnotetext{
1 A more concise analysis would have compared the mean rates of association with children (number of associations/number of daughters versus the same for sons) by parents in each of the status groups. In the majority of cases, however, parents had either no sons or no daughters, making calculation of such rates impossible by introducing zeros into denominators. Data were accordingly grouped as in Tables 1 and 2. Use of the instantaneous scan technique should have randomized observations on individuals with respect to whether or not they behaved in the expected way.
} 
Unless a higher proportion of parental investment was consistently conveyed when parents spent less time with their children, Trivers and Willard's prediction is consistent with these results.

Finally, information on another essential investment component, the flow of resources (Fisher 1958; Trivers 1972), would be an important supplement. It may be unreasonable, though, to assume that association frequency does not coincide with resource flow. Members of Ifaluk households that share food with one another (Betzig and Turke, n.d.), for example, associate significantly more often than members of households that do not $(t=2.033, p=0.0447)$. Orientation has been used in a number of studies as an indicator of willingness to help (e.g., Chagnon and Bugos 1979; Hames 1979; Seyfarth and Cheney 1984).

\section{CONCLUDING REMARKS}

At this point, Trivers and Willard's seems the best explanation for the observed bias in association patterns. Although the literature on human investment patterns, including residence and inheritance, is vast (e.g., Radcliffe-Brown and Forde 1950; Schneider and Gough 1961; Goody 1976), none of it that we are aware of predicts or explains this complex of association preferences with sons and daughters dependent upon parental status.

Evidence from 104 societies suggests that in matrilineal, as well as patrilineal, societies, the reproductive success of high-status sons exceeds that of their sisters (Betzig 1986b). And, in all human societies, parental condition can have important effects on both sons' and daughters' reproductive potential, irrespective of rules of residence (cf. Altmann 1980; Silk 1983; Fairbanks and McGuire 1985). This suggests that the pattern of investment described here probably has been adaptive in both kinds of societies historically. Whether or not it is presently on Ifaluk remains an interesting question. ${ }^{2}$ One tentative suggestion that it might be comes from the observation that chiefs and salaried men successfully affect the probability, possibly in part by spending more time with them, that their sons get reproductively beneficial salaried jobs (Turke and Betzig 1985).

Present patterns of parent-child association on Ifaluk may be consistent with the prediction that high-status parents will favor sons, because such a pattern has been adaptive over the course of evolutionary history (see Symons 1979, 1985), or because it is adaptive presently (see Alexander 1979, 1985), or both. Human historical evidence, suggesting that high-status sons generally have outreproduced their sisters, is consistent with the first; and the evidence that Ifaluk chiefs, possibly by association with their sons, now help them get reproductively beneficial salaried jobs, is consistent with the last.

\footnotetext{
${ }^{2}$ We hope eventually to be able to address this question accurately by obtaining complete genealogical data of greater depth.
} 
But we must note that the inheritance of chiefly status on Ifaluk from a mother's brother, rather than from a father, appears to be inconsistent with both the present pattern of parent-child association, and with Trivers and Willard's prediction. Though this form of inheritance has not been the rule in human societies, neither is Ifaluk an isolated case (e.g., Murdock 1972). The African Gold Coast Ashanti, for example, are even more enigmatic; kings kept to themselves up to thousands of women, and when they died bequeathed that right to their sister's sons (Rattray 1927). Presumably, a man with sufficient power to attract more women than anyone else might have more of what it takes to keep them, at very least the heir producers among them, from cuckolding him. Some evidence supports this assertion (Dickemann 1981; Betzig 1986b), and so contradicts the hypothesis that matrilineal inheritance may be associated with or caused by low confidence of paternity (e.g., Alexander 1974; Gaulin and Schlagel 1980; Flinn 1981). That a social position associated with reproductive privilege is ever given by a man to his sister's son, rather than to his own, remains to us one of the striking incongruities between Darwinian theory and the evidence from human societies.

Thanks to M. Dickemann, R. Trivers, R. Wrangham, T. Caro, M. Borgerhoff Mulder, W. Holmes, M. Flinn, anonymous reviewers, and especially to R.D. Alexander, for helpful comments on the paper, to $M$. Dow for statistical criticism, and to G. Mesher for computational advice. Research on Ifaluk was made possible in part by grants from the Wenner-Gren Foundation to L.B. and the National Science Foundation to P.T.; writing was made possible in part by the generous allocation of computing time and office space by R.D. Alexander, W. Dawson, and the University of Michigan Museum of Zoology, and by a grant from the University of Michigan to L.B.

\section{REFERENCES}

Alexander, R.D. The evolution of social behavior. Annual Review of Ecology and Systematics 5:325-383 (1974).

Darwinism and Human Affairs. Seattle: University of Washington Press, 1979.

- A biological interpretation of moral systems. Zygon. 20: 3-20 (1985).

Alkire, W.H. Land tenure in the Woleai. In Land Tenure in Oceania, H.P. Lundsgaarde, ed. Honolulu: University of Hawaii, 1974, pp. 39-69.

Altmann, J. Observational study of behaviour: Sampling methods. Behaviour 49: 227-267 (1974).

- Baboon Mothers and Infants. Cambridge: Harvard University Press, 1980.

Bates, M., and Abbott, D. Coral Island. New York: Scribner's, 1958.

Betzig, L.L. Despotism and Differential Reproduction: A Darwinian View of History. Hawthorne, NY: Aldine, 1986b.

- Redistribution: Equity or exploitation? In Human Reproductive Behaviour, L.L. Betzig, M. Borgerhoff Mulder, and P.W. Turke, eds. London: Cambridge University Press, $1986 \mathrm{a}$, in press.

Betzig, L.L., and Turke, P.W. Measuring time allocation: Observation and intention. Current Anthropology 27 (1986), in press.

—_ Food sharing on Ifaluk (unpublished). 
Boone, J.L. Parental investment and elite family structure in preindustrial states: A case study of late medieval-early modern Portuguese genealogies. American Anthropologist 88 (1986), in press.

Burrows, E.G., and Spiro, M.E. An Atall Culture. New Haven: HRAF, 1953.

Chagnon, N.A., and Bugos, P. Kin selection and conflict: An analysis of a Yanomamo ax fight. In Evolutionary Biology and Human Social Behavior: An Anthropological Perspective, N.A. Chagnon and W. Irons, eds. North Scituate, MA: Duxbury, 1979, pp. 213-237.

Clutton-Brock, T.H., and Albon, S.D. Parental investment in male and female offspring in mammals. In Current Problems in Sociobiology, King's College Sociobiology Group, ed. London: Cambridge University Press, 1982, pp. 233-247.

Dickemann, M. Female infanticide, reproductive strategies, and social stratification: A preliminary model. In Evolutionary Biology and Human Social Behavior: An Anthropological Perspective, N.A. Chagnon and W. Irons, eds. North Scituate, MA: Duxbury, 1979, pp. 321-367.

- Paternal confidence and dowry competition: a biocultural analysis of purdah. In Natural Selection and Social Behavior, R.D. Alexander and D.W. Tinkle, eds. New York: Chiron, 1981, pp. 417-438.

Fairbanks, L.A., and McGuire, M.T. Relationships of vervet mothers with sons and daughters from one through three years of age. Animal Behaviour 33: 40-50 (1985).

Fisher, R.A. The Genetical Theory of Natural Selection, 2nd ed. New York: Dover, 1958.

Flinn, M.V.D. Uterine versus agnatic kinship variability and associated cousin marriage preferences: an evolutionary biological analysis. In Natural Selection and Social Behavior, R.D. Alexander and D.W. Tinkle, eds. New York: Chiron, 1981, pp. 439-475.

Gaulin, S.J.C., and Schlagel, A. Paternal confidence and parental investment: a cross cultural test of a sociobiology hypothesis. Ethology and Sociobiology 1: 301-309 (1980).

Goody, J. Production and Reproduction. London: Cambridge University Press, 1976.

Hames, R.B. Relatedness and interaction among the Ye'kwana: A preliminary analysis. In Evolutionary Biology and Human Social Behavior: An Anthropological Perspective, N.A. Chagnon and W. Irons, eds. North Scituate, MA: Duxbury, 1979, pp. 239-249.

Lutz, C. Emotion words and emotional development on Ifaluk Atoll. Ph.D. dissertation, Harvard University, 1980.

The expression of emotion on Ifaluk. American Ethnologist 9: 113-125 (1982).

Murdock, G.P. Ethnographic Atlas. New Haven: HRAF, 1972.

Radcliffe-Brown, A.R., and Forde, D., eds. African Systems of Kinship and Marriage. London: Oxford University Press, 1950.

Rattray, R.S. Religion and Art in Ashanti. Oxford: Clarendon, 1927.

Schneider, D., and Gough, K., eds. Matrilineal Kinship. Berkeley: University of California Press, 1961.

Seyfarth, R., and Cheney, D. Grooming, alliances, and reciprocal altrusim in vervet monkeys. Nature 308: 541-543 (1984).

Silk, J.B. Local resource competition and facultative adjustment of sex ratios in relation to competitive abilities. American Naturalist 121: 56-66 (1983).

Symons, D. The Evolution of Human Sexuality. New York: Oxford University Press, 1979.

- If we're all Darwinists, what's the fuss about? In Sociobiology and Psychology: Issues, Ideas, and Findings, C. Crawford et al., eds. Hillsdale, NJ: Erlbaum, 1985.

Trivers, R.L. Parental investment and sexual selection. In Sexual Selection and the Descent of Man, B. Campbell, ed. Hawthorne, NY: Aldine, 1972, pp. 136-179.

- Social Evolution. Menlo Park, CA: Benjamin/Cummings, 1985.

- - and Willard, D.E. Natural selection of the ability of parents to manipulate the sex of offspring. Science 179: 90-92 (1973).

Turke, P.W. Fertility determinants on Ifaluk and Yap: Tests of Darwinian and economic explanations of demographic transitions. Ph.D. dissertation, Northwestern University, 1985 .

- and Betzig, L.L. Those who can do: Wealth, status, and reproductive success on Ifaluk. Ethology and Sociobiology 6: 117-125 (1985).

Van den Berghe, P.L., and Mesher, G. Royal incest and inclusive fitness. American Ethnologist 7: 300-317 (1980). 
Voland, E. Human sex-ratio manipulation: historical data from a German parish. Journal of Human Evolution 13: 99-107 (1984).

- Parental investment and reproductive potential: a study of a German parish. In Human Reproductive Behaviour, L.L. Betzig, M. Borgerhoff Mulder, and P. Turke, eds. London: Cambridge University Press, 1986, in press. 